SERVIÇO DE PATOLOGIA E CLINICA MÉDICAS (1.a cadeira)

Diretor: Prof. Dr. S. N. Piratininga

\title{
ACTINOMICOSE DA MANDÍBULA EM UM CÃO (*)
}

(ACTINOMYCOSIS OF THE MANDIBLE IN A DOG)

\author{
Max Ferreira Migliano \\ ÂNGELo V. STOPIGLiA \\ Assistente \\ Veterinário interno \\ 2 estampas ( 4 figuras)
}

A actinomicose é afecção de incidência rara na espécie canina. Os casos descritos são em pequeno número e, ainda, alguns dêles, pelas características que apresentam, talvez devessem ser incluidos, mais pròpriamente, no grupo das estreptotricoses.

Observaçōes com diagnóstico aparentemente seguro de actinomicose foram relatadas por Torrance (citado por Manninger "in" Hutyra, Marek, e Manninger), Kitt (1919), Slavin (1938), Eroms (1939, citado por Martin), Martin (1942), Wimite (1945) e Ginseerg e Little (1948), que descreversm o processo, com localização visceral, serosa ou subcutânea. Apenas dois casos de actinomicose com localização óssea foram descritos: o de VAcierta, em 1882, e o de FumaGALLI, relatado em 1903, ambos citados por BRION.

$\mathrm{O}$ caso descrito por VAchetTa refere-se à observação de um cão que apresentava tumefação no segmento posterior do ramo horizontal direito da mandíbula, com orifício abrindo-se na regiāo submaxilar. Histològicamente, pôde ser verificada, no tecido inflamatório, a presença de gigantócitos e de filamentos de aspecto miceliano, ora conglomerados, lembrando figuras em forma de margarida, ora em posição radiada e mostrando as extremidades espessadas, assemelhando-se a esporos. A observação de Fumagalli diz respeito a um cão que apresentava também formação de aspecto tumoral com fístulas, no maxilar inferior. O exame microscópico revelou as rosetas características do Actinomyces.

\section{OBSERVAÇÃO}

Em 27-7-1948 trouxeram-nos para exame, um cão, Pointer, com 15 meses de idade, macho, procedente de Campinas. Há dois meses que seu proprietário havia observado aparecimento de um tumor na região mandibular direita com

(*) Apresentado à VI Reuniäo Anual de Veterinária, São Paulo, 22-25/9/1949. 
fístulas por onde era eliminada, no início, massa de aspecto purulento, de côr cinzento-amarelada e, depois, de aspecto sero-sanguiinolento. Nos últimos dias emagrecimento acentuado do animal.

Ao exame verificamos: abatimento, grau extremo de caquexia. Pele sêca, elasticidade diminuida. Gânglios retrofaringeanos, preparotideano e submaxilar, do lado direito, aumentados de volume e sensíveis. Mucosas aparentes desccradas. Temperatura $39^{\circ}, 3$. Pulso 100 , regular.

Aumento de volume acentuado da regiāo têmporo-mandibular direita, apresentando orifícios de saída de trajetos fistulosos: um, na região masseteriana, dirigindo-se profundamente até à parte inferior da mandíbula; outro, na região subparotideana, com direção oral; pelos dois orifícios, escoamento de líquiiido serohemorrágico. Exoftalmia ligeira, edema da conjuntiva e corrimento ocular seromucoso no lado da regiāo afetada (fig. 1).

A palpação, percebia-se a borda inferior do corpo da mandíbula, de superfície bastante irregular, espessada cêrca de duas vêzes o tamanho normal, desde a articulação têmporo-mandibular até à altura dos pré-molares.

Dificuldade de preensão dos alimentos por impossibilidade de movimertação da mandíbula.

Exame radiológico - A radiografia revelou modificações estruturais e proliferação de tecido ósseo no ramo direito da mandíbula, desde o último pré-molar ao segundo molar, estendendo-se pelo seu ramo montante à àrticulação têmporomandibular (fig. 2).

EXAMES DE LABORATORIO

Exame de fezes - Foram verificados numerosos ovos de Ancilostoma caninum e Trichuris vulpis, em exame com enriquecimento.

Exame de urina:

Volume $-20 \mathrm{~cm}^{3}$ (extraída por cateterismo).

Côr - amarelo citrina.

Aspecto - turvo.

Densidade - 1.015.

Reação - alcalina.

Urobilina - muito aumentada.

Indicão - levemente aumentado.

Sedimento - Elementos organizados: raras células epiteliais chatas e ra. ros leucócitos.

Elementos não organizados: numerosos grânulos de carbonato de cálcio. 
Exame de sangue:

Hemoglobina -- 58\% (Sahli).

Hemácias - 3.780.000.

O hemograma revelou ligeira leucocitose com monocitose:

Leucócitos - 16.480 .

Contagem diferencial:

\begin{tabular}{|c|c|}
\hline infócitos & \\
\hline Monócitos & 10 \\
\hline Neutrófilos & $\begin{array}{l}\text { (segmentados: } 65,5 \%) \\
\text { (bastonetes: } \quad 4.0 \% \text { ) }\end{array}$ \\
\hline sinófilos & \\
\hline
\end{tabular}

Exame do corrimento da fistula - 0 exame microscópico, a fresco, revelou duas formações, com o aspecto das rosetas de Actinomyces.

Foi feita biópsia do músculo masseter e do gânglio submaxilar, verificando-se no músculo, tecido de granulação contendo raras formações semelhantes a colônias de Actinomyces e no gânglio, ùnicamente hiperplasia do tecido linfóide.

Diagnóstico - O O diagnóstico de actinomicose, suposto pelos dados do exame clínico, positivou-se com os resultados da biópsia e do exame do corrimento da fístula. Por motivos alheios à nossa vontade, não nos foi possivel a obtenção da cultura do material para evidenciar a espécie do Actinomyces.

\section{TRATAMENTO}

Ao tratamento clássico, pelo iodeto de potássio em solução a $10 \%$, administrando-se por via endovenosa $10 \mathrm{~cm}^{3}$ diàriamente, associamos a penicilina, 100.000 U.O. ao dia, segundo as recentes observações de sua ação sôbre o Actinomyces.

Como tratamento adjuvante, sôro glicosado e extrato de fígado por via parenteral e, citrato de ferro amoniacal, por via oral.

0 estado de caquexia se acentuou e o animal morreu no sexto dia de tratamento.

\section{NECROSCOPIA *}

No ramo direito da mandíbula, formação de aspecto tumoral com abertura de orifício da fístula, na superfície inferior.

(*) Agradecemos ao Dr. Paulo Bueno, do Instituto Biológico, pelos exames anátomo a bisto-patólogicos e pela valiosa cooperaçãa 
Enfisema pulmonar bilateral.

Anemia de alto grau.

Preparada a peça do maxilar inferior, foi revelado processo de osteoperiostite com formação de grande número de osteófitos no têrço posterior do maxilar inferior direito, atingindo e provocando anquilose da articulação têmporo-mandibular (fig. 3.).

Exame histo-patológico — "Secções de várias regiões da formação tumoral demonstram ser esta, em base, representada por tecido conjuntivo denso, envolvendo áreas de infiltração inflamatória recente, contendo, por vêzes, microabs. cessos.

O estudo histológico destas áreas revela tecido constituido por células jovens, com grande número de capilares néo-formados, ao lado de intensa infiltração de células de tipo plasmocitário, de macrófagos, de histiócitos e de granulócitos neutrófilos.

Os microabscessos contêm, por vêzes, em seu interior, estruturas semelhantes às observadas nos aglomerados de Actinomyces. Observadas com grande aumen. to, embora reproduzam o aspecto de colônias típicas daquele parasita, não demonstram características bastante definidas, aparentando encontrarem-se em estado de degeneração.

Finalmente, ao redor das áreas descritas e disseminados por todo o tecido néo-formado, vêem-se focos celulares, contendo grande número de gigantócitos, com diversos núcleos conglomerados ou dispostos em longas cadeias longitudinais. O estudo minucioso dêstes elementos revela serem êles originários de núcleos de fibras musculares mantidas em sequestro no intimo do tecido inflamatório" (figura 4).

\section{CONCLUSAO}

Em conclusão, a apresentação dêste caso se justifica pela raridade da ocorrência da actinomicose, particularmente de sua localização óssea, na espécie canina.

\section{ABSTRACTS}

The authors relate a case of actinomycosis localized in the right branch of the mandible of a dog. The interest lies on the rarity of the disease in such an animal. 
CITAÇÃO BIBLIOGRAFICA

Rron, A. - 1939 - L'actinomycose du chien et du chat. Rev. Méd. Vét., Toulouse, 91: 121-59

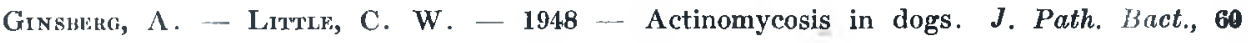
(4) :563-72

Intrya, F. v. - MareK, J. - Man ninger, R. - 1947 - Patología y terapéutica especinles de los animales domésticos. 'Trad. 8.a ed. al. 1: Enfermedades infecciosis: 542. I abor, S. A., 1947

K!'T, 'Th, - 1919 - Aktinomykotische Brustfellentzïndung beim Hunde. Monatshefts f. prakt. Tierheilkunde, 29:518-26

Man'tix, H. M. 1912 - Actinomycosis of the dog and cat. Univ. Ponn. Bull, 87:15-9

Si.avix, I). 1938-An actinomycotic disease in the dog. Vet. Rec., 50(34):1083

WHI'te, II. S. - 1945 - . - Actinonycosis of the lungs in a dog. Cornell Jet., 35:72-4 

M. F. Migliano e A. V. Stopiglia - Actinomicose em căo

Estampa

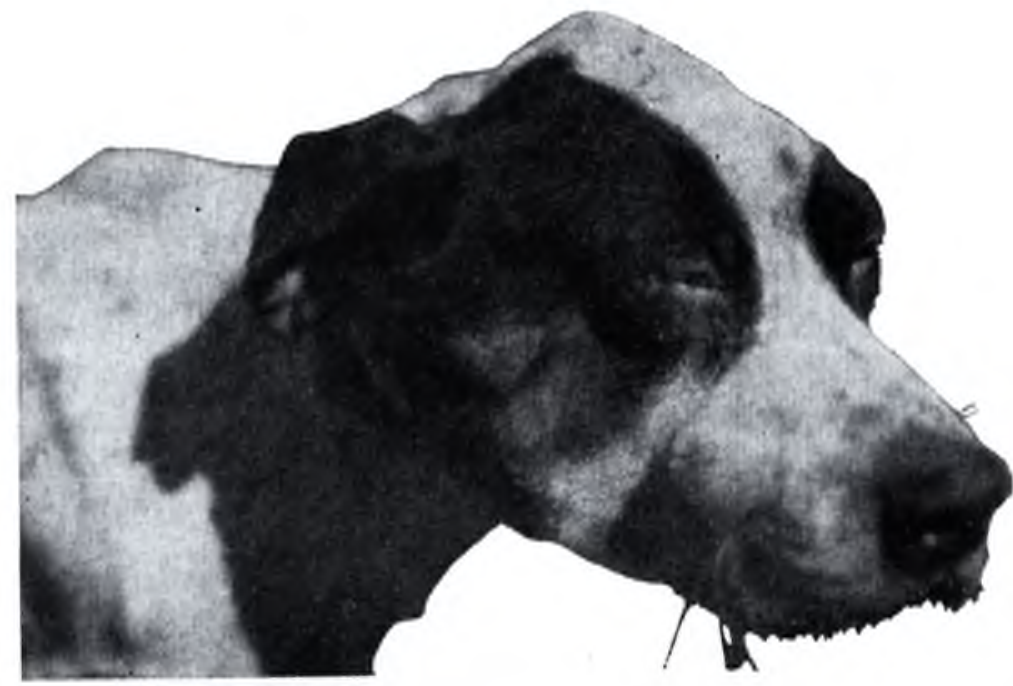

Fig. 1

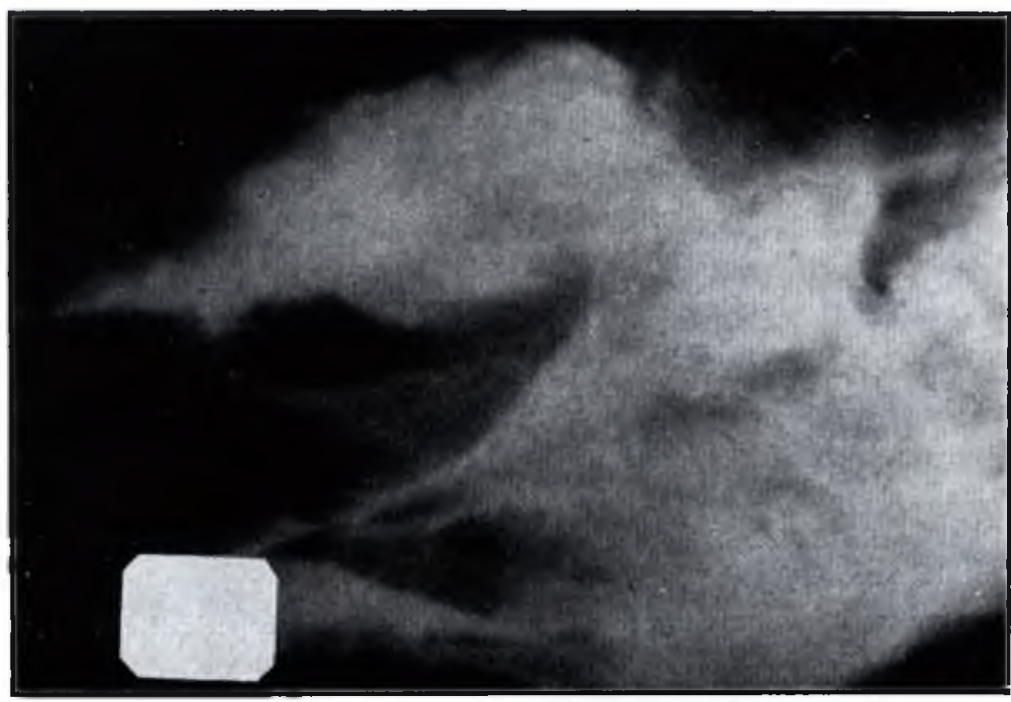

Fig. 2 
Rev. Fac. Med. Vet. S. Paulo - Vol. 4, fase. 1, 1949

Estampa II

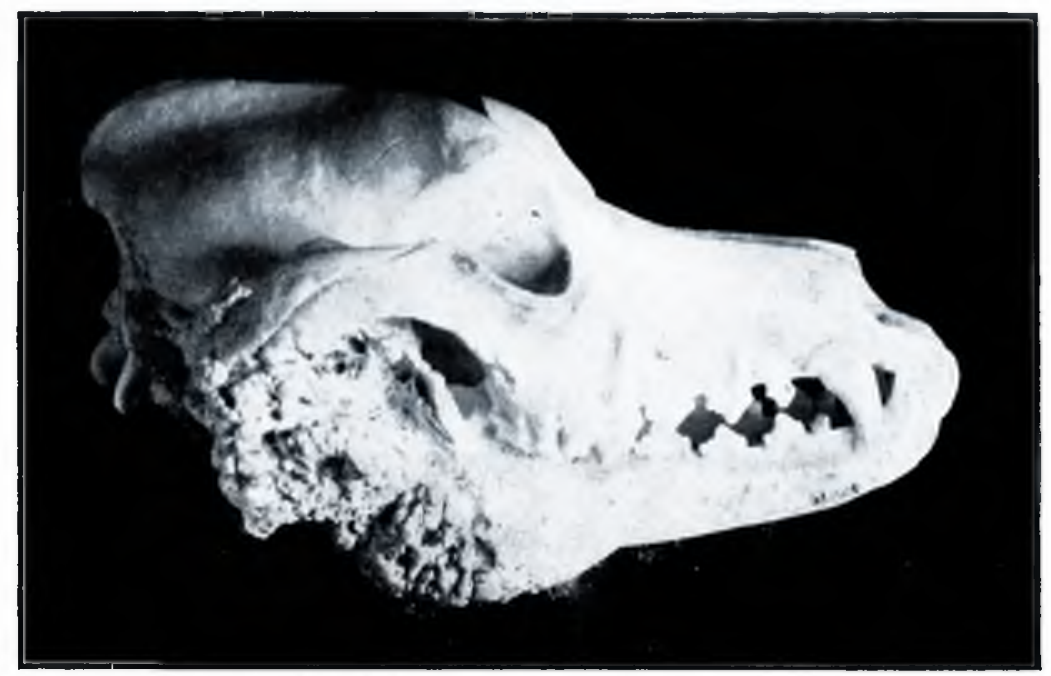

Fig. 3

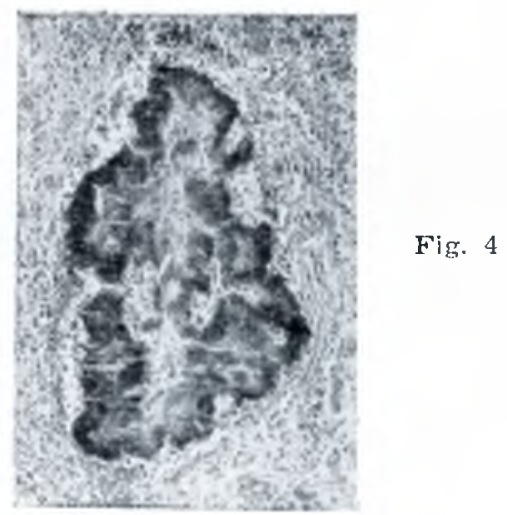

EXPLICAÇÃO DAS FIGURAS

I'ig. I - liotografia do animal, notando-se o ammento de volume da regiño temporomandibular dircila.

Fig. 2- Radiografia da mandíbula revelando modificaceóses restruturais e proliferitceño do tecido ósseo.

Fig. 3 - Fotografia do crâneo mostrando o processo de osteoperiostite com formação le osteófitos.

Fig. - Microfotografia de uma seção do osso da mandibula, apresentando colónia de Actinomyces. 